University of St. Thomas, Minnesota

UST Research Online

2016

\title{
Longitudinal Effects of Computer-mediated Communication Anxiety on Interaction in Virtual Teams
}

\author{
Robert M. Fuller \\ University of Tennessee, Knoxville, rfuller2@utk.edu \\ Chelley M. Vician \\ University of St. Thomas, vici9046@stthomas.edu
}

Susan A. Brown

University of Arizona, suebrown@eller.arizona.edu

Follow this and additional works at: https://ir.stthomas.edu/ocbacctpub

Part of the Accounting Commons

This Article is brought to you for free and open access by the Accounting at UST Research Online. It has been accepted for inclusion in Accounting Faculty Publications by an authorized administrator of UST Research Online. For more information, please contact asle4660@stthomas.edu. 


\title{
Longitudinal Effects of Computer-Mediated Communication Anxiety on Interaction in Virtual Teams
}

\author{
Robert M. Fuller \\ University of Tennessee \\ Haslam College of Business \\ Knoxville, TN 37996 \\ rfuller2@utk.edu \\ 865-974-1749 \\ Chelley Vician \\ University of St. Thomas \\ Opus College of Business \\ St Paul, MN 55105 \\ cvician@stthomas.edu \\ 651-962-5551 \\ Susan A. Brown \\ University of Arizona \\ Eller College of Management \\ Tucson, AZ 85721 \\ suebrown@eller.arizona.edu \\ 520-626-8330
}

[This paper is the Pre-proof, Accepted version of the manuscript now published by IEEE.

The published work is available in IEEE Xplore ${ }^{\circledR}$ : https://doi.org/10.1109/TPC.2016.2583318 ]

(C) 2016 IEEE. Personal use of this material is permitted. Permission from IEEE must be obtained for all other uses, in any current or future media, including reprinting/republishing this material for advertising or promotional purposes, creating new collective works, for resale or redistribution to servers or lists, or reuse of any copyrighted component of this work in other works. 


\title{
Longitudinal Effects of Computer-Mediated Communication Anxiety on Interaction in Virtual Teams
}

\begin{abstract}
Abstract -- Research problem: Organizations continue to rely upon virtual teams, yet knowing how, and for how long, individual members' computer-mediated communication (CMC) anxiety affects virtual team interactions and performance outcomes is not well-known. Research questions: (1) What is the relationship between CMC anxiety and virtual team participation? (2) How does this relationship influence the perceptions of individual performance? (3) Does this relationship persist over time? Literature review: A literature review including communication and media structures, input-mediator-output team effectiveness, and individual CMC anxiety elements indicate researchable negative effects upon virtual team interaction and participation in CMC environments. Higher levels of individual CMC anxiety could dampen participation quantity, participation type (task vs. social), participation quality, and perceptions of individual performance. Further, the initial negative interactions and behaviors could persist over time. Methodology: This quantitative quasi-experimental study involved surveying, observing, and coding the interactions of 22 virtual project teams (consisting of 110 individuals) over a span of four months. The teams used a CMC tool with shared file space and discussion boards to coordinate database design and implementation work. Data were collected from questionnaire surveys, individual message postings, and team project scores. Individual message postings were coded to measure participation quality (task focus and topic introductions) and participation quantity (message count and words per message). Data were analyzed using repeated-measures multivariate analyses along with follow-up univariate statistical testing. Results and conclusions: The results indicate that individuals with higher levels of CMC anxiety participated less, sent fewer task-oriented messages, introduced fewer novel topics, and were rated more poorly by team members on their performance compared to individuals with lower levels of CMC anxiety. The results also show that CMC anxious individuals do send relatively more social-oriented messages, perhaps to compensate for typical apprehensive communication behaviors in a virtual team environment. Additionally, participation quality and quantity and perceptions of performance by CMC anxious team members do not significantly improve, even with repeated interactions over CMC. Although study participants evidenced high engagement with the project tasks, the study is limited by its use of student subjects. The study suggests the importance of team leaders and role definitions for virtual teams, in order to counteract potential unintended effects of CMC technology use masking actual participation and contribution of virtual team members. Future research could investigate the efficacy of interventions for reducing the negative impacts of $\mathrm{CMC}$ anxiety in virtual team performance, as well as the influence of individual structures such as CMC anxiety in the use of CMC and team structures in the virtual team environment.
\end{abstract}

Keywords: Computer-mediated communication, communication apprehension, anxiety, virtual teams, longitudinal, performance, evaluation, Media Synchronicity Theory (MST), CMC anxiety 


\section{Longitudinal Effects of Computer-Mediated Communication Anxiety on Interaction in Virtual Teams}

\section{Introduction}

Organizations continue to utilize virtual teams to leverage individual expertise that is difficult to arrange in a collocated environment. An individual's participation in a virtual team influences the team's performance outcomes, yet deep knowledge about an individual's communication behaviors within a virtual team is limited. Further, in a virtual team, an individual's communication is mediated by computing technologies. The nature of the interaction may have unintended and previously unidentified effects on individual participation and performance in a virtual team. Managers, as professional communicators, need to understand the dynamics of such individual influences upon an individual's virtual team participation and performance.

Organizational reliance on teams has increased substantially. One of the major reasons cited for this is the improved performance that results from uniting individuals who bring unique knowledge to the task or project at hand [1], [2], [3], [4]. Through an individual's communication of this unique knowledge, teams are expected to have improved performance over that of individuals operating alone. However, the most appropriate team members for a specific task are often separated by time and/or distance. Fortunately, with the diffusion of information and communication technology (ICT), organizations are able to leverage technology investments by implementing distributed work arrangements such as virtual teams [5], [6], [7], [8]. Virtual teams allow organizations to achieve the performance benefits of teams and overcome many of the limitations of having experts geographically or temporally distributed while reducing the travel and real estate costs often necessary to support team work [7], [9], [10]. 
Virtual teams are generally defined as groups of people that are geographically and/or temporally dispersed and use some combination of ICT to perform a task [3], [5], [8]. Through the use of computer-mediated communication (CMC) embedded in ICTs, individuals on virtual teams share relevant information necessary for task completion. For most virtual teams, CMC is likely the primary mechanism for interacting and contributing to team performance. However, to attain the synergistic benefits of having geographically distributed experts on a virtual team, it is important for organizations to ensure broad-based participation in the use of the CMC.

Virtual teams face many of the same challenges as face-to-face (FTF) teams. However, the virtual environment has the potential to mitigate or magnify certain problems. Some research has shown that individuals on virtual teams communicate more and participate more evenly or democratically than their FTF counterparts [11], [12], [13]. In contrast, other research has identified factors that may negatively influence the degree to which individuals participate in interactions facilitated by CMC [14], [15], [16], [17]. In particular, Brown et al.'s [14] study demonstrated a negative impact on interaction behaviors due to CMC anxiety, an individual anxiety arising from use of the computer system, communicating, and communicating via computer. Given the significant organizational reliance on virtual teams, it is important to understand the degree to which these individual-level anxieties influence virtual team interactions and performance outcomes, and whether these effects are temporary or long lasting. As organizations seek synergistic performance by uniting experts in disparate locations, knowing the factors that influence interaction behaviors could help organizations select individuals for inclusion on virtual teams in order to achieve optimal performance outcomes. Understanding the temporal persistence of these behaviors can also help organizations determine appropriate 
interventions. If, for example, these effects are temporary, then organizations can work to minimize the negative behaviors and resulting performance impacts until they disappear. If these effects are more persistent throughout the life of a team, then organizations must more closely consider individual characteristics for virtual team membership, and utilize stronger interventions to promote participation on a virtual team and obtain successful outcomes.

We aim to extend the work of Brown, et al. [14] as well as others' work on CMC impact on virtual team participation behaviors [11], [18], [19], [20], [21], [22], [23] in three important ways. First, we open up the black box of virtual team participation and examine it from a quantity and quality perspective. We expand the measurement of quantity to include message length and the measurement of quality to identify novel contribution. Second, we empirically test the association between reduced participation and performance assessments. Although Brown, et al. [14] made the assumption that less participation would have negative impacts on performance, in the current study, we specifically evaluate this relationship. Finally, we examine the nature of CMC anxiety over time in order to understand whether or not it has an enduring impact on participation and performance.

In summary, virtual teams have the potential for greater performance due to their ability to connect non-co-located experts in a cost-effective manner. Furthermore, the use of CMC to connect members in virtual teams can encourage and support more democratic participation among virtual team members. However, the very nature of the interaction, via CMC, may also have unintended and previously unidentified effects on individual participation and subsequent performance. The purpose of this study is to understand more fully the nature of CMC anxiety 
and its influence on an individual's participation and performance in a virtual team. Specifically our research questions are: What is the relationship between CMC anxiety and virtual team participation, how does this relationship influence the perceptions of individual performance, and does this influence persist over time?

The remainder of this paper continues as follows. We begin with a review of relevant literature and development of hypotheses associated with our research questions. We then describe the research methodology used followed by an explanation of the results obtained. The paper concludes with a discussion of findings, limitations of the research, and suggestions for future research.

\section{Literature Review}

This section of this paper reviews the relevant literature on virtual teams' use of media capabilities found in computer mediated communication (CMC) technologies and the inputmediator-output team effectiveness framework. This theoretical foundation is presented first, and helps to identify technological and individual characteristics that influence virtual team interactions and subsequent performance outcomes applicable to the research questions of interest. This foundation is followed by a description of the hypothesized relationships between individual CMC anxiety characteristics, their influence on virtual team interactions, and subsequent influence on virtual team member perceptions of individual performance.

Theoretical Orientation. Teams that require the use of CMCs to interact and generate outcomes, virtual teams, provide a unique environment where individuals can work together, 
mediated through technology. Prior research suggests that the use of communication structures available in CMC by a virtual team may improve participation quality and quantity [24], [25]. To identify ICT technology structures relevant to virtual team interaction we utilize the media structures (capabilities) as identified in Media Synchronicity Theory (MST) [26]. MST identifies five capabilities of media that influence the ability of virtual team members to work together with a shared focus (synchronicity). The five structures are parallelism, reprocessability, rehearsability, transmission velocity, and symbol set variety.

In this research we are particularly interested in CMC that support asynchronous communication for virtual teams that are separated by both time and distance [27]. As a result, for asynchronous communication, we focus on the CMC structures of parallelism, rehearsability and reprocessability as these have been found to be most relevant and are identified as being significant capabilities of media that impact the transmission of information, and have direct implications for the processing of this information [26]. These three features have been shown to have an impact on social interactions, influencing the quantity and quality of participation when available to virtual team members [11].

Parallelism allows individuals to transmit and receive information to multiple recipients at the same time [26], [28], thus increasing the number of communication episodes that can occur simultaneously. The overall impact of parallelism is an increase in the overall quantity of participation as individuals are able to send more messages without the turn-taking constraints associated with FTF communication [29]. Rehearsability allows individuals to review and edit their own communications before sending them to a recipient [26]. Rehearsability can encourage 
greater quality of participation as individuals can consider more deeply and thoroughly the messages they send before sending, with less concern about misinterpretation and with more assurance of accuracy in their own message [30]. Reprocessability refers to the ability to reexamine or re-process messages that were previously submitted [26], [28]. Reprocessability has the potential to increase the quantity and quality of participation by enabling team members to recall prior messages accurately and triggering more novel and creative comments and discussion items [26], [31].

Prior research on team effectiveness and performance has typically adopted an Input-MediatorOutput (IMO) framework [32]. This framework highlights the team contextual elements and interaction processes and facilitating factors that mediate and influence performance and affect outcomes in teams. Although various models of team performance and interaction derived from this model exist, we apply this particular framework due its general applicability across teams and contexts, and its representation of the constructs of interest in our research. Furthermore, it allows us to specifically examine and hypothesize the influence of repeated interactions on ongoing interaction processes and outcomes. Our research model, presented in Figure I, highlights the specific constructs that we examine in the research, as identified in the IMO framework. The three major constructs of interest, individual characteristics -- mediating processes and performance outcome perceptions -- are explained below.

Input - Individual Team Member Characteristics - CMC Anxiety. In any communication context, the individuals participating have certain characteristics that impact their ability or motivation to contribute to the interaction taking place. For this research, we focus specifically 
on those individual-level anxieties related to communication and the use of a computer as these have been found to impact the degree and manner in which individuals feel competent and willing to participate using CMC tools [14], [15]. Furthermore, the effective and efficient use of CMCs by virtual teams could potentially be impaired if individuals do not overcome these anxieties.

Brown et al. [14] introduced computer-mediated communication anxiety, a specific form of anxiety targeted at the CMC environment. It refers to the "fear or apprehension associated with actual or anticipated use of information technology to communicate with others” (p. 83). CMC anxiety essentially acknowledges the interactive effect of anxieties related to communicating and using computer technology. It incorporates elements of oral and written communication apprehension and computer anxiety. Brown et al. [14] found a significant relationship between CMC anxiety and attitude toward using CMC tools, which in turn impacted use of these tools. Their results clearly demonstrated that CMC anxiety is a more proximal anxiety mediating the relationship between general forms of apprehension and anxiety in the context of using CMC tools.

Process - Virtual Team Participation - Quantity and Quality. Prior research has attempted to understand the degree to which CMC has had an influence on individual participation. In considering participation, we are most interested in how individual participation varies in terms of quantity and quality. Participation quantity is a volume measure that is concerned with the number of messages or the size of messages that individuals share when interacting [33]. Prior research has typically examined participation from a volume perspective [34], [35]. Participation 
quantity provides a starting point to gauge the amount of involvement of team members on a virtual team. Further, as a readily observable measure, participation quantity indicates an individual's expended effort in team interaction. Participation quality is the contribution to performance outcomes provided by an individual's interaction. It is a value measure that is concerned with the contribution that the messages sent by a team member makes to task outcomes [36]. Quality can be seen in the introduction of novel ideas or topics for consideration by the team, as well as in messages focused on task rather than unrelated social communications [37], [38].

In terms of quantity of participation, research has shown that teams interacting over CMC participate more than their FTF counterparts and rate their own participation higher [4], [11], [12], [13], [39]. Further, research suggests that the more asynchronous a communication medium is, the longer the messages sent through that medium tend to be [26], [33]. Likewise, participation by individuals in mediated teams tends to be more or less democratic, with similar levels of contributions made by members [40], [41], [42]. The preceding indicates that quantity of participation in teams facilitated by CMC tends to be greater than teams interacting FTF. This is particularly important as it supports the view that as CMC allows more information to be available to the team, better outcomes on task should result [4], [43].

Results regarding the quality of participation of members in CMC facilitated teams compared to FTF teams are not as clear. In some studies, the quality of participation has been found to be higher in teams that are facilitated through CMC. Specifically, it is well observed that taskfocused communication is often greater in CMC teams; therefore the quality of participation as it 
relates to a task is often greater for CMC teams than for FTF teams [4], [44], [45]. Teams interacting via CMC have been found to generate more critical discussions and more arguments when working on a task [12], [46]. Likewise, projects conceived by teams interacting via CMC were better received by management than projects conceived by FTF teams [11]. There is, however, other research suggesting that although participation quantity in CMC teams is better or no different than in FTF teams, decision outcomes are no different and potentially worse [47], [48], [49]. Additionally, ad hoc, one-time FTF teams working on decision-making tasks were found to share more information and make better decisions than their CMC counterparts [50], [51]. However, in general, research supports the notion that the features found in CMCs provide a mechanism to encourage higher quality participation from team members, especially for team members working over longer periods on real world tasks.

As individuals on virtual teams interact through the use of CMC, it is possible that this repeated interaction process could result in enhanced processes and outcomes. Prior research has shown that over time with repeated use, virtual team performance and effectiveness at using the CMC can improve as individuals on the virtual team gain experience and understanding with the technology, their team members, and the task [25], [52]. However, it is also possible that given repeated interactions with a CMC, individual characteristics may play a stronger role, discouraging gains in experience and understanding, and exacerbating the influence that individual characteristics, particularly CMC anxiety, have on the interaction, resulting in no increase in or diminished participation on the virtual team. This unintended consequence, particularly with communication anxiety, has been reported in prior communication research [53], [54], [55]. It is not certain if repeated use will be associated with increased or decreased 
participation. However, many anxieties have been shown to be resilient to change over time, suggesting that it is unlikely that without specific interventions, simple repeated use will not reduce the influence of anxieties on behavior.

Output - Virtual Team Performance - Team Member Performance Perceptions. Ultimately of concern is team performance and team affect as these are key outcomes in any team task [32]. Although much of the research on virtual teams has attempted to determine the impact of interacting virtually on team performance [56], our research is particularly interested in perceptions developed by individuals of their team members based on the performance they perceive. In virtual teams, where the primary manner of interaction is text-based, assessments of team member performance are likely heavily influenced by perceived communication behaviors. In teams where individuals have anxiety that can influence their contribution to the team, others' perceptions can influence how their contribution to team performance is assessed. Prior research has shown that perceptions of contribution to team task activities is associated with higher perceptions of team member performance [57].

In summary, the CMC features of parallelism, rehearsability, and reprocessability have the potential to alter the manner in which individuals separated by distance and time interact as they work on a task asynchronously in a virtual team. Specifically, research has demonstrated that each of these features can impact both the quantity and quality of the participation of virtual team members. As seen in prior comparisons of CMC supported virtual teams to FTF teams, the provision and use of these three features resulted in a greater quantity of participation in terms of words and messages sent by team members, as well as a greater quality of participation in terms 
of novel idea contribution and task-focused messages. These process characteristics, especially over time with repeated use, are likely to be influential in the perceptions of performance by other virtual team members. Given the primary evidence of interaction in an asynchronous team being text-based messages, these key participation indicators are likely to have greater salience to team members.

\section{Figure I}

\section{Research Model}

Input-Mediator-Output Team Effectiveness Framework
Inputs
Mediators
Outputs

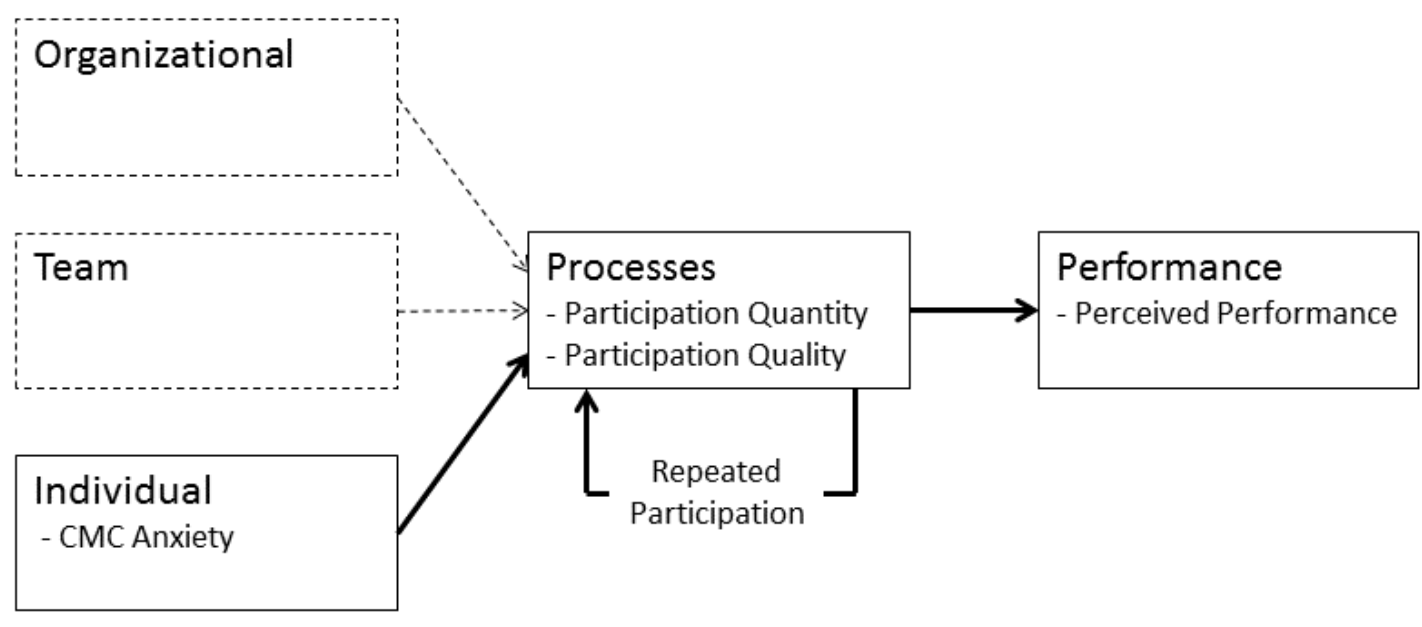

Not examined in this research.

Adapted from Mathieu et al., 2007

Selection of Literature for Review. Based on the theoretical foundation described above, we searched the literature on virtual team interaction as it related to individual characteristics on communication apprehension in computer mediated communication. Furthermore, we examined this literature for studies that focused on the manner in which individual communication 
characteristics influence the quality of information shared between virtual team members and participation patterns. Considering participation process characteristics, we identified and included relevant research that identified relationships between participation processes and perceptions of performance outcomes. We were particularly interested in those studies that would not only indicate how these factors interacted to influence outcomes, but how these characteristics and interactions persisted over time with subsequent interactions.

\section{CMC Anxiety and Participation Quantity. A great deal of research suggests that} communication apprehensive individuals avoid communicating [54], [55], [58]. Likewise, computer anxiety research demonstrates avoidance behavior on the part of computer anxious individuals [59], [60], [61], [62]. Although Karahanna et al. [15] did not examine use, they found that communication apprehension influenced perceptions of relative advantage, a construct that has been linked to behavioral intention and use behavior in technology adoption research [63]. More specifically related to the CMC context, Brown et al. [14] demonstrated that CMC anxiety negatively impacted CMC attitude, which in turn was associated with decreased CMC use. Most research on individual anxiety/apprehension effects highlights the significance of early encounters with the object of the anxiety/apprehension [53], [64], [65]. Overall, as research is reasonably consistent on the relationship between anxiety/apprehension, quantity of participation, and initial encounters, we offer the following hypotheses related to virtual team participation quantity:

Hypothesis 1a: Initially (during phase 1), individuals with high CMC anxiety will participate less (send fewer messages) via computer mediated communication technology than those with low CMC anxiety 
Hypothesis 1b: Initially (during phase 1), individuals with high CMC anxiety will participate less (send fewer words per message) via computer mediated communication technology than those with low CMC anxiety.

CMC Anxiety and Participation Quality. Communication in virtual teams can be categorized into two distinct types: social and task-oriented [44], [66], [67]. It is generally accepted that teams need both categories of individual communication to function successfully [26], [68], even though task-oriented participation is identified as most important for team performance [38]. For individuals with communication apprehension, any type of participation, task or social, can be challenging. Communication apprehensive individuals engage in less task-related participation for fear of poor evaluations by others involved in the communication [54], [55], negatively impacting quality of participation. Likewise, communication apprehensive individuals have been shown to provide fewer social messages in an attempt to minimize self-disclosure [55]. For those individuals with CMC anxiety, we would expect similar outcomes when interacting in a mediated environment. Therefore we hypothesize:

Hypothesis 2a: Initially (during phase 1), individuals with high CMC anxiety will send fewer task-oriented messages via computer-mediated communication technology than those with low CMC anxiety.

Hypothesis 2b: Initially (during phase 1), individuals with high CMC anxiety will send fewer social-oriented messages via computer-mediated communication technology than those with low CMC anxiety.

One anticipated outcome from the use of virtual teams is an improvement in performance due to synergistic addition of different individuals working on the task. For performance improvement to occur, individuals need to share information, participate in ways that are meaningful for the team, and contribute to the achievement of goals, an important part of participation quality. Participation quality can be seen in the form of interjections of new ideas, beliefs, and opinions 
into the team discussion [69]. Research on communication coherence and team performance both identify the communication act of introducing new ideas as important to team performance [37], [70], [71]. Although prior research suggests that an important benefit of CMC technology lies in its ability to allow distributed individuals to interact as they work on a task, research on communication apprehension suggests that apprehensive individuals are more likely to make irrelevant contributions to the team communication, interject ideas and interrupt less often, and offer submissive statements during team interaction resulting in lower participation quality [54], [55]. Therefore we include the following hypothesis:

Hypothesis 2c: Initially (during phase 1), individuals with high CMC anxiety will have lower participation quality (introduce fewer novel communication topics) than those with low CMC anxiety when interacting via CMC.

CMC Anxiety and Perceived Performance. Initially, apprehensive individuals would be expected to have lower quantity and quality of participation in a virtual team in terms of communication and contribution of new ideas and opinions to the team task. Prior research suggests that apprehensive individuals, due to their lower participation, will be perceived as contributing less to the team task than their less-apprehensive team members and would be perceived by their teammates as being lower performing [54], [72], [73]. As a result, we would expect that individuals with high CMC anxiety would be rated as performing poorly relative to other members of their team. Therefore we hypothesize:

Hypothesis 3: Initially (during phase 1), individuals high in CMC anxiety will be rated as lower in performance by the other members on their team.

CMC Anxiety Persistence on Participation Quantity. Prior research has shown equivocal and sometimes conflicting results on the persistence of apprehension-influenced communication 
behaviors. Some research on oral communication apprehension has suggested that with repeated interactions or experience, communication apprehension may diminish [53], [58]. Essentially, with repeated social interactions, individuals will experience less apprehension about the communication act, develop new social structures and perceptions about participation, and engage in participation more frequently and with more ease. However, other research on writing apprehension and computer anxiety supports a more trait-based view of apprehension, showing that repeated interactions may actually exacerbate apprehensions, increasing the likelihood that individuals will experience heightened apprehension, and refrain from the activity of interest [53], [54], [55], [65].

Given the focus of this study—a CMC-enabled virtual team working on a project—we anticipate that several structures in the virtual team environment will be important in determining the participation behavior of virtual team members, particularly for those with CMC anxiety. On one hand, CMC provides a set of structures that enable individuals with CMC anxiety to better transmit and process information. Parallelism, rehearsability, and reprocessability structures support virtual team member participation quantity and quality by allowing them to participate in communication without concern of interrupting others, to reconsider and edit communications potentially increasing their confidence and minimizing evaluation apprehension regarding the communications they send, and to review and revisit prior communications to help generate better and more novel contributions to the team task [26]. Likewise, teams develop social structures that facilitate and constrain the manner in which the team members should communicate with one another. These team norms develop over time, and with repetition, become expected patterns for interaction [74]. Given a task that requires team member 
participation and contribution for completion, these norms should value increased participation quantity and quality. Finally, contrary to the above, individual characteristics such as CMC anxiety provide a strong individual structure that guides participation. These individual structures are a strong influence on individual behavior. Considering the nature of CMC anxiety, it is uncertain how much change in the enacted structures would be expected with repeated interaction.

Similar to prior trait-oriented research in written communication apprehension and computer anxiety, individuals with repeated interactions over the CMC would not change in the level of CMC anxiety they experience and as a result, would continue to communicate or interact in the same manner they did previously. We suggest three reasons for this. First, recent research in CMC anxiety has shown that although oral communication apprehension is a key component of CMC anxiety in a social setting [14], [75], in a work-based setting where individuals are evaluated on their contribution to a task we expect that CMC anxiety might exhibit similar apprehension-inducing properties to written communication apprehension, and thus be more trait-like. Second, it has been observed that individuals in virtual teams may feel a sense of isolation from the team, and therefore may not visibly contribute to team outcomes [76]. Individuals who already feel anxious about communicating over CMC may have these feelings exacerbated in a virtual team. Finally, as individuals interact via CMC, they will develop their own expectations and experiences using the various structures available in the CMC (namely parallelism, rehearsability and reprocessability). It may be that the unfaithful enactment (or lack thereof) of these structures leads to even less participation as individuals develop individual norms for usage of these structures. Consequently, we expect that individuals would approach 
the CMC in a manner that would be more similar to a written communication medium, subject to the same reinforcing negative beliefs with repeated interaction, and will develop inappropriate non-use behavior of the CMC. Over time, the impact of CMC anxiety should have a continuing negative effect on participation quantity and quality, such that individuals with higher initial levels of CMC anxiety would maintain prior levels of participation quantity and quality, similar to those initially exhibited during phase I of the project. Therefore we hypothesize:

Hypothesis 4a: During phase 2, individuals with high CMC anxiety will participate less (send fewer messages) via computer mediated communication technology than those with low CMC anxiety

Hypothesis 4b: During phase 2, individuals with high CMC anxiety will participate less (send fewer words per message) via computer mediated communication technology than those with low CMC anxiety.

CMC Anxiety Persistence on Participation Quality. As teams interact over time, research has shown that team members typically develop a consensus set of expectations (i.e., pattern of social interaction) for participation behavior that establishes the norms for team interactions [24], [74]. As teams become established, communication norms for participation develop. These norms indicate the expected and appropriate interaction behaviors to be exhibited by team members. However, given the written nature of the communication to be sent over the CMC, we would anticipate a negative effect on team member participation for those team members experiencing high levels of CMC anxiety. As much of the communication on a team project or task is subject to evaluation, we expect that CMC anxious team members would continue to avoid communication, to minimize evaluation. Particularly for task and novel communications as those are most clearly subject to evaluation for team members as they contribute directly to project goals, we would expect CMC anxious individuals to participate less. As a result, we 
would anticipate that over time, the individual structures restricting communication would be stronger than team norms, reflected in lower levels of participation quality exhibited by team members higher in CMC anxiety. Therefore we hypothesize:

Hypothesis 5a: During phase 2, individuals with high CMC anxiety will send fewer task-oriented messages via computer-mediated communication technology than those with low CMC anxiety.

Hypothesis 5b: During phase 2, individuals with high CMC anxiety will send fewer socialoriented messages via computer-mediated communication technology than those with low CMC anxiety.

Hypothesis 5c: During phase 2, individuals with high CMC anxiety will have lower participation quality (introduce fewer novel communication topics) than those with low CMC anxiety when interacting via computer mediated communication technology.

CMC Anxiety Persistence on Perceived Performance. Over time, apprehensive individuals would be expected to continue their repetition of these existing patterns of communication and contribute fewer ideas and opinions to the team discussion unlike their lower apprehensive team members. Prior research suggests that apprehensive individuals, due to their lower participation, will be perceived as performing less well than their less-apprehensive team members and would be perceived by their teammates as being lower performing [54], [72], [73]. As a result, we would expect that individuals with high CMC anxiety would be rated as contributing less and underperforming relative to other members of their team. Therefore we hypothesize:

Hypothesis 6: During phase 2, individuals high in CMC anxiety will be rated as lower in performance by the other members on their team.

\section{Methodology}

In this section we describe the approach used to test the research hypotheses. This section begins with an explanation of our choice of research methodology, and continues with a description of the study participants. Next the study project setting, timeline and description are provided, 
followed by a description of the CMC used. The section concludes with an explanation of how the data for the study were collected and assessments of reliability and validity of the data.

Choice of Research Methodology. To test our hypotheses, a quasi-experiment was utilized to assess the difference in communication process characteristics and perceptions of performance by level of CMC Anxiety. The method is quasi-experimental because the comparison groups were formed based on level of CMC Anxiety measured, yielding two comparison groups, one higher in CMC Anxiety and the other lower in CMC Anxiety. The quasi-experimental design allowed us to control for other individual characteristics as well as team-level characteristics.

Study Participants. One hundred ten undergraduate students at three North American universities enrolled in introductory database courses participated in this longitudinal study. The study received approval from Institutional Review Boards for Human Subjects Research at all three universities. All participants signed consent forms agreeing to participate in the study. Participants were organized into 22 five-member virtual project teams subject to the constraint that each team had at least one member from each of the three participating universities. The virtual project teams completed a database design and implementation project over a period of sixteen weeks.

Setting, Project Timeline, and Project Description. Project team members were geographically dispersed, necessitating the use of CMC tools for the coordination and support of virtual team activities to complete the database design and implementation project. Deliverables of the project included a conceptual model, normalized database design, and a Microsoft Access 
database implementation including forms, reports, and raw SQL queries, as well as a final project summary report. The project case mirrored a real-world scenario for the design and development of a system to track applicant recruitment by corporations and was of moderate difficulty for the participants (e.g., use of extended entity-relationship diagramming structures and more than 10 normalized tables).

The project consisted of two different phases, each with deliverables to be submitted. Each project phase required virtual team collaboration and communication for the purpose of developing project deliverables, a deliverable submission, and evaluative feedback.

CMC and Computing Technologies. A commercially developed, widely available web-based groupware tool was used by all virtual project teams for collaboration. Team members used a shared workspace to coordinate communication via a discussion board feature and shared file space for the posting of project work. Each team was responsible for managing its own shared file space, including the development of directories/folders and management of draft versions of deliverables. Participants posted project deliverables in the shared file space for evaluation purposes. Participants received site-specific training on the use of the groupware tool as well as a training handout (with screen shots) that demonstrated how to use features to support virtual collaboration work.

The tool met the criteria previously described for a CMC tool to support virtual team interactions, providing parallelism, rehearsability, and reprocessability. As a discussion board, individuals could post permanent messages that were immediately available for team members to 
read. Individuals did not have to wait for others messages to be posted before posting their own messages, thus representing a parallelism structure, allowing multiple simultaneous communications to occur. The interface to post messages consisted of a form that was filled out and not sent to the discussion board until the virtual team member pushed "send". Therefore, team members could revise and edit their messages before they were viewable by others, representing a rehearsability structure. Finally, the discussion board feature of the tool automatically archived any posted messages, thus participants had ready access to past discussion threads and topics, providing a critical repository for participants, representing a reprocessability structure.

How Data Were Collected. This section describes how the data for the study were collected. It begins by identifying and defining the measures collected in the study. This section concludes with an explanation, for each measure, of the process by which the data was collected.

Measures. A variety of mechanisms were used to measure the variables in this research. Webbased survey forms were provided to the participants to collect questionnaire data, particularly to collect individual demographics and CMC anxiety. Message postings from the team workspaces were also collected. Message postings could contain one or more topics; topics being distinct subjects discussed in a message posting. Over 5000 message postings were captured and coded to measure individual participation quality (task focus and topic introductions) and participation quantity (number of messages and words per message). Finally, the scores of the team project were captured to measure team performance. See Table I for a listing of variables, definitions, and measures used in the research. 
Table I

Variables, Definitions, and Measures

\begin{tabular}{|c|c|c|}
\hline Variable & Definition & Measures \\
\hline \multicolumn{3}{|c|}{ INDIVIDUAL STRUCTURES } \\
\hline CMC Anxiety & $\begin{array}{l}\text { The fear or apprehension } \\
\text { associated with actual or } \\
\text { anticipated use of information } \\
\text { technology to communicate with } \\
\text { others. }\end{array}$ & $\begin{array}{l}\text { Established scale from } \\
\text { Brown, et al. [14]. }\end{array}$ \\
\hline \multicolumn{3}{|c|}{ SOCIAL INTERACTION/INTERACTION PROCESSES } \\
\hline $\begin{array}{l}\text { Participation } \\
\text { Quantity }\end{array}$ & $\begin{array}{l}\text { The amount of communication } \\
\text { sent by a team member. }\end{array}$ & $\begin{array}{l}\text { Number of messages sent. } \\
\text { Average number of words per } \\
\text { message sent. }\end{array}$ \\
\hline \multirow{3}{*}{$\begin{array}{l}\text { Participation } \\
\text { Quality }\end{array}$} & \multirow{3}{*}{$\begin{array}{l}\text { The contribution to performance } \\
\text { outcomes provided by the types of } \\
\text { interactions of a team member. }\end{array}$} & $\begin{array}{l}\text { Number of task-oriented } \\
\text { topics submitted. }\end{array}$ \\
\hline & & $\begin{array}{l}\text { Number of social-oriented } \\
\text { topics submitted. }\end{array}$ \\
\hline & & $\begin{array}{l}\text { Number of topic introductions } \\
\text { (topic starts) submitted. }\end{array}$ \\
\hline \multicolumn{3}{|c|}{ PERFORMANCE OUTCOMES } \\
\hline $\begin{array}{l}\text { Perceived } \\
\text { Performance }\end{array}$ & $\begin{array}{l}\text { The perception of a team } \\
\text { member's participation in creating } \\
\text { the deliverable for each project } \\
\text { phase as assessed by the other } \\
\text { team members. }\end{array}$ & $\begin{array}{l}\text { Deviation of individual } \\
\text { performance score from team } \\
\text { performance score. }\end{array}$ \\
\hline
\end{tabular}

Computer-mediated communication anxiety. The scale for CMC anxiety was developed for this line of research and has been shown to have reasonable reliability [14]. The scale's wording was revised to reflect the web-based groupware tool used by the teams.

Participation quantity. Participation quantity is an interaction volume measure that indicates an individual's amount of participation. Participation quantity is evident in the number of messages 
and words an individual chooses to send to participate and reflects his/her communication abilities and competencies [77] in a very visible form of virtual team interaction. Communication exchanges were examined for the number of words in a message, and the number of messages sent by each participant. For each participant within each phase (phase 1 and phase 2), the messages and their word contents were summed (or averaged for an average words/message measurement) to obtain the two measures for participation quantity. These values were then normalized to remove variations due to differing participation requirements for the phases and to allow for comparison between phases.

Participation quality. Participation quality is an interaction value measure that indicates the contribution to performance outcomes provided by the social interactions of an individual. The content of a communication exchange provides tangible evidence of how an individual is interacting with others in the communication exchange, and is a direct means of assessing the quality of the participation [37], [69], [70], [71]. The content provides an evaluation of an individual's contribution to the team's collaboration efforts. Prior studies have illustrated the importance of the type of content (social or task focus) [67], [78] and the content's novelty of contribution to enhance topic discourse (topic introduction) [37], [69].

To measure participation quality, a coding scheme was developed to analyze the interactions. Each sent message posting was examined to determine the type of topic (or topics if the message contained more than one), topic uniqueness, and topic sequence. For each message, topics were coded as T if task-oriented and S if socially-oriented. Each topic in a message was also examined for uniqueness. Each topic was numbered sequentially as it was introduced. New topics were 
coded with a new number and continuing topics were coded with the number previously assigned to that topic. This is similar to the identification of a thread that represents a related set of messages on a particular topic. Within each thread, individual statements were numbered in sequence to distinguish the introduction of a new topic from restatements of the topic, agreements, and other types of non-novel topic discussion. Therefore, when a new topic was introduced, its topic number was incremented from the prior topic number, and was given a 1 indicating that it was the first statement about the topic. Subsequent statements about that topic would be given the same topic number, but the sequence number would be incremented.

Although other coding forms exist, our interest was in the identification of distinctly new topics for discussion, as these likely indicate higher levels of contribution to the task due to their novel content [37], [69]. An example of the coding scheme is provided in the Appendix.

Perceived performance. Individual performance is calculated as the deviation from the team score that an individual receives as a result of their team member assessments. It is a measure of the perception of an individual's participation in creating the deliverable for each project phase as assessed by the other team members. Teams received a score for their deliverable. This score was then adjusted for each member based on the ratings given by the other team members. For example, a team may have received a score of 80 for a deliverable; however, the individual's score may be adjusted downward from 80 (e.g., 75 indicating a deviation of 5) depending on the assessment by his or her team members. This deviation value (5) was normalized to facilitate comparisons in performance deviations between different deliverables. 
How the Data Were Analyzed. To analyze each hypothesis, initially the data collected via survey for CMC anxiety and the coded interaction data were assessed for reliability and validity. Once the data were validated, we first performed repeated-measures MANOVA for the dependent variables (individual performance deviation, \# messages, \# social topics, \# task topics, \# unique topics, and average words per message). For this analysis, CMC anxiety was the between-subjects factor, and project phase (phase 1, phase 2) was the within-subjects factor. The analyses also accounted for correlation among the individuals on the same team by including a team effect nested within treatment and using the team effect error term [see 79]. Due to the limitation of requiring fully captured information for all repeated measures, the analyses are based on results from 74 participants, 33 rated as lower apprehensive and 41 rated as higher apprehensive. Based on the results of the initial MANCOVA, follow-up univariate tests to ascertain differences in the dependent variables due to CMC anxiety were performed. Finally, the hypotheses were directly tested using Bonferroni adjusted t-tests with overall family alpha of 0.05 to determine if the differences between groups were in the direction hypothesized and significant.

Ensuring Reliability and Validity. In the current study, the alpha reliability score for CMC anxiety, 0.858, is consistent with prior work and well above Nunnally’s [80] suggested 0.70 cutoff. Based on the results of the scale, we divided participants into two groups based on the mean CMC anxiety value, with those participants with a CMC anxiety score greater than the mean in the higher CMC anxiety group and those participants with a CMC anxiety score less than the mean in the lower CMC anxiety group. Two coders, blind to the study's objectives, each coded half of the teams, and three additional teams each, providing $27 \%$ overlap in the coding. 
This overlap was examined to determine agreement for the coded observations. The two coders were in agreement for $87 \%$ of the observations (Cohen’s Kappa $=0.82$ ) indicating adequate reliability of the coding. The results from the coding were aggregated for each participant to measure the total number of task, social, and introductory (starts) messages submitted for both of the phases (phase 1 and phase 2). These values were normalized to remove variations due to differing participation requirements for the different phases and to allow for comparison between phases.

\section{Results}

In this section, we discuss the results obtained from analysis of the data collected from the quasiexperiment. First we provide information on the participants and variable statistics, followed by overall results of the MANOVA and univariate testing, and conclude with the results obtained from the hypothesis tests.

Participants. Given our interest in individual levels of participation and contribution to team interactions and performance, our level of analysis focuses on the individual. Participants were $72 \%$ male with an average age of 22.7 years (s.d. $=4.9$ ), and an average of 4.0 years of work experience $($ s.d. $=4.4)$. Statistical tests found no differences between subjects in the two participant conditions in terms of gender, age, or work experience. Means and standard deviations for the dependent variables are reported in Table II. 
Table II

Means (s.d.) for Dependent Variables

\begin{tabular}{|c|c|c|c|c|c|c|c|}
\hline \multirow[b]{3}{*}{$\begin{array}{l}\text { Proj. } \\
\text { Phase }\end{array}$} & \multirow[b]{3}{*}{$\begin{array}{l}\text { CMCAnx } \\
\text { Level } \\
\text { Group }\end{array}$} & \multicolumn{6}{|c|}{ Dependent Variables } \\
\hline & & \multicolumn{2}{|c|}{$\begin{array}{c}\text { Participation } \\
\text { Quantity }\end{array}$} & \multicolumn{3}{|c|}{$\begin{array}{c}\text { Participation } \\
\text { Quality }\end{array}$} & \multirow{2}{*}{$\begin{array}{c}\begin{array}{c}\text { Performance } \\
\text { Outcome }\end{array} \\
\text { Perf. } \\
\text { Dev. }\end{array}$} \\
\hline & & $\begin{array}{c}\# \\
\text { Messages }\end{array}$ & $\begin{array}{c}\text { Avg } \\
\text { Words/Msg }\end{array}$ & $\begin{array}{l}\text { \# Task } \\
\text { Topics }\end{array}$ & $\begin{array}{c}\# \\
\text { Social } \\
\text { Topics } \\
\end{array}$ & $\begin{array}{c}\# \\
\text { Topic } \\
\text { Starts }\end{array}$ & \\
\hline \multirow[b]{2}{*}{ P1 } & Low & $\begin{array}{c}0.33 \\
(0.93)\end{array}$ & $\begin{array}{c}0.04 \\
(0.86)\end{array}$ & $\begin{array}{c}0.33 \\
(0.82)\end{array}$ & $\begin{array}{l}-0.20 \\
(1.01)\end{array}$ & $\begin{array}{c}0.35 \\
(0.76)\end{array}$ & $\begin{array}{l}-0.15 \\
(0.90)\end{array}$ \\
\hline & High & $\begin{array}{l}-0.28 \\
(0.94)\end{array}$ & $\begin{array}{l}-0.12 \\
(0.87)\end{array}$ & $\begin{array}{l}-0.26 \\
(0.83)\end{array}$ & $\begin{array}{c}0.11 \\
(1.02)\end{array}$ & $\begin{array}{l}-0.28 \\
(0.77)\end{array}$ & $\begin{array}{c}0.23 \\
(0.91)\end{array}$ \\
\hline \multirow{2}{*}{$\mathrm{P} 2$} & Low & $\begin{array}{c}0.31 \\
(0.65)\end{array}$ & $\begin{array}{c}0.11 \\
(0.84)\end{array}$ & $\begin{array}{c}0.34 \\
(0.72)\end{array}$ & $\begin{array}{l}-0.02 \\
(0.79)\end{array}$ & $\begin{array}{c}0.44 \\
(0.77)\end{array}$ & $\begin{array}{l}-0.24 \\
(0.98)\end{array}$ \\
\hline & High & $\begin{array}{l}-0.10 \\
(0.66) \\
\end{array}$ & $\begin{array}{l}-0.21 \\
(0.85) \\
\end{array}$ & $\begin{array}{l}-0.16 \\
(0.72) \\
\end{array}$ & $\begin{array}{l}-0.01 \\
(0.80) \\
\end{array}$ & $\begin{array}{c}-0.29 \\
(0.77) \\
\end{array}$ & $\begin{array}{c}0.22 \\
(0.99) \\
\end{array}$ \\
\hline
\end{tabular}

Overall Results. The results from the overall repeated measures MANOVA indicated that there was a significant main effect for the $\mathrm{CMC}$ anxiety variable $(\mathrm{F}(6,29)=4.256, p=0.003)$, however, there was no significant main effect of phase $(\mathrm{F}(6,29)=0.129, p=$ n.s. $)$ nor a significant interaction between the CMC anxiety and phase $(\mathrm{F}(6,29)=0.717, p=$ n.s. $)$ Therefore, CMC anxiety was found to have a direct effect on the dependent variables. Phase alone was not significant, nor was the interaction term (phase * CMC Anx). Table III presents the overall MANOVA results. 
Table III.

Overall MANOVA Results

\begin{tabular}{lccccc}
\hline Independent Variable & $\begin{array}{c}\text { Wilk's } \\
\text { Lambda }\end{array}$ & $\mathbf{F}$ & df & $\begin{array}{c}\text { Error } \\
\text { df }\end{array}$ & p-value \\
\hline CMC Anx & 0.532 & 4.256 & 6 & 29 & 0.003 \\
Phase & 0.974 & 0.129 & 6 & 29 & 0.992 \\
CMC Anx * Phase & 0.871 & 0.717 & 6 & 29 & 0.639 \\
Team (CMC Anx) & 0.001 & 2.200 & 228 & 181 & 0.001 \\
Phase * Team (CMC Anx) & 0.001 & 1.729 & 228 & 181 & 0.001 \\
\hline
\end{tabular}

Given the significant main effects of CMC Anxiety, additional univariate tests were performed to see the specific effect of the independent variables on the outcome variables (see Table IV). The results of the univariate tests indicate that CMC anxiety had a direct effect on the number of messages sent $(p=0.004)$, number of task topics sent $(p=0.001)$, number of topic introductions (starts) sent $(p=0.001)$ and individual performance deviation $(p=0.019)$.

Table IV

Follow-up Univariate Results for Independent Variable CMC Anxiety

\begin{tabular}{lcc}
\hline Dependent Variables & $\mathbf{F}$ & $\boldsymbol{p}$-value \\
\hline \# Messages & 9.623 & 0.004 \\
Avg Words/Msg & 2.053 & 0.161 \\
\# Task Topics & 12.441 & 0.001 \\
\# Social Topics & 0.831 & 0.368 \\
\# Topic Starts & 17.955 & 0.001 \\
Performance Deviation & 6.063 & 0.019 \\
\hline
\end{tabular}

The results of the repeated-measures MANOVA and univariate tests supported the significance of our primary independent variables on most of the outcome measures. Given these results, we performed further analyses to test each of the hypotheses using Bonferroni adjusted t-tests with the overall family alpha level set to 0.05 . 
The results show that in the initial project phase, individuals with higher CMC anxiety (a) sent significantly fewer messages than did individuals with lower CMC anxiety $(p=0.010$; supporting H1a), (b) sent fewer messages with a task-orientation than individuals with lower CMC anxiety ( $p=0.004$; supporting H2a), and (c) introduced fewer novel or introductory content messages than individuals with lower CMC anxiety ( $p=0.001$; supporting H2c). The results do not show any differences in the number of words per message (failing to support H1b) or the number of social messages (failing to support H2b). Finally, in the initial phase, individuals with high CMC anxiety had a somewhat larger deviation (negative) from the team performance score ( $p=0.079$; moderately supporting H3).

During phase 2, the results show that individuals with higher levels of CMC anxiety continued to send significantly fewer messages than their low CMC anxiety counterparts $(p=0.012$; supporting $\mathrm{H} 4 \mathrm{a}$ ), continued to send fewer task-oriented messages than individuals with low CMC anxiety ( $p=0.006$; supporting H5a), and sent significantly fewer novel or introductory content messages ( $p=0.001$; supporting H5c). In phase 2, individuals with higher levels of CMC anxiety also sent messages with fewer words per message than the individuals with low CMC although this was not significantly different anxiety ( $p=0.12$; failing to support H4b). There continued to be no significant difference in the number of socially oriented messages sent (failing to support H5b). Finally, the results show that the individual performance deviation for CMC anxious individuals was still greater (i.e., they were still rated lower) than less anxious individuals in phase 2 ( $p=0.056$; moderately supporting H6). See Table V for a summary of the hypothesis test results. 
Table V

Hypothesis Test Results

\begin{tabular}{llcc}
\hline Test & & p-values* & Results \\
\hline At Phase 1 & & \\
H1a: & HA < LA \# Messages & 0.010 & Supported \\
H1b: & HA < LA \# Words/Message & 0.437 & n.s. \\
H2a: & HA < LA \# Task Topics & 0.004 & Supported \\
H2b: & HA < LA \# Social Topics & 0.200 & n.s. \\
H2c: & HA < LA \# Topic Starts & 0.001 & Supported \\
H3: & HA > LA Performance Deviation & 0.079 & Weak support \\
& & & \\
At Phase 2 & & 0.012 & Supported \\
H4a: & HA < LA \# Messages & 0.117 & n.s. \\
H4b: & HA < LA \# Words/Message & 0.006 & Supported \\
H5a: & HA < LA \# Task Topics & 0.996 & n.s. \\
H5b: & HA < LA \# Social Topics & 0.001 & Supported \\
H5c: & HA < LA \# Topic Starts & \\
H6: & HA > LA Performance Deviation & 0.056 & Weak Support \\
\hline * p-values are Bonferroni adjusted, alpha level of 0.05. & \\
Note: LA = Low CMC Anxiety, HA = High CMC Anxiety &
\end{tabular}

\section{Conclusions, Limitations and Suggestions for Future Research}

In this section, the results obtained from the hypothesis tests are presented and their contribution to our understanding of the influence of individual characteristics, namely CMC anxiety, on individual participation and perceptions of performance. We begin with conclusions drawn from these results and their implications for research and practice. We follow providing limitations of the research, and conclude with suggestions for future research.

\section{Conclusions}

In this study, we set out to understand the relationship between CMC anxiety and virtual team participation, how the relationship influences perceptions of individual performance, and whether or not the relationship persists over time. The results demonstrated that differences in CMC anxiety were associated with different participation behaviors and performance 
assessments. As hypothesized, individuals with higher levels of CMC anxiety generally sent fewer messages, sent fewer task-oriented messages, introduced fewer novel topics, and were rated by their team members as having lower levels of performance. Although the project was an important one and had value to the participants, CMC anxious individuals still did not contribute as much as less anxious individuals, especially in terms of task-oriented communication and novel contributions to the team. Furthermore, these differences persisted as participants with higher CMC anxiety exhibited similar behaviors in the first and second project phases of the project.

These results are consistent with prior research indicating that individuals with higher levels of CMC anxiety will interact less via the CMC tools [14]. However, the results extend prior research in four important ways. First, they identify specific differences in the manner of interaction (i.e., social vs. task comments, topic introductions vs. topic responses), providing insights into important elements of participation differences. Second, the results empirically demonstrate that this behavior differential is associated with perceptions of lower performance by other team members. Third, the results shed light on the persistence of these behaviors with repeated exposure to CMC tools. Finally, we find that enacted individual structures can have a much stronger influence on an individual's virtual team participation behaviors than team social structures and CMC structures that would encourage a more homogenizing of individual participation levels, especially with repeated interaction.

We found no significant differences between high and low anxious individuals for the number of socially oriented messages sent. This is surprising given that prior research suggests 
communication apprehensive individuals would be less likely to self-disclose in the CMC environment. However, there are two possible explanations as to why this might be the case. First, individuals with higher CMC anxiety experienced relatively less apprehension sharing social information as compared to task information (since higher CMC apprehensive individuals sent significantly fewer task-oriented messages). It may be that in a project-oriented virtual environment, the apprehension related to self-disclosure is less than the apprehension related to evaluation of task-oriented messages. To give the appearance of being part of the team, individuals with high CMC anxiety perhaps found it easier to disclose social information, which may be more difficult to assess for accuracy, than to provide task-oriented information that is more subject to evaluation.

Individuals with higher CMC anxiety contributed fewer novel ideas in the course of discussion. Prior research has shown that greater contributions to discussion can be seen in the introduction of new ideas as opposed to responses, agreements, and reiterations of previously presented ideas [37]. Thus, it is not surprising that the participation quality of CMC anxious individuals was evaluated poorly relative to other team members. This is consistent with prior research that shows individuals with communication apprehension and computer anxiety are rated as lower in performance by their peers [54], [72], [73]. However, the results of this study provide greater insight into why this is the case. Specifically, the poor evaluations are likely due to issues surrounding the quality and quantity of participation, particularly the amount of task and novel contributions to the team. 
Our results show that this pattern of participation remained consistent over time, even with repeated use of the CMC technology. Research in communication apprehension suggests that with repeated experience, apprehensions may be reduced [53], [58]. If this were the case in this research, we would expect to see a relative increase in participation behavior such as more taskoriented messages, longer messages, and more introductory or novel messages, over time. This did not occur. In contrast, some research has suggested that repeated experience with the apprehension causing environment may actually be negatively reinforcing, causing additional avoidance or withdrawal behavior [54], [55], particularly where computers are concerned [62]. In this case, we would expect to see diminishing participation behaviors over time, which also was not the case. Instead, we found unchanging communication behavior. Our research model would suggest the reason for this lack of change is that the early anxiety and negative interactions influenced later social interactions. It is likely that the initial pattern of participation enacted by CMC anxious individuals was adhered to for the duration of the project.

Based on the pattern of results, we believe that individual structures that constrain individual behavior have a stronger effect on individual participation and performance in the context of a virtual team. Although our model identifies various sources of structure that facilitate and constrain teams as they interact using technology, we identify a strong, dominating influence, individual structures, that can overcome the potential benefits achievable from the development of team social structures and the availability of technology facilitating structures. We found that individual structures (in this case CMC anxiety) can have an overpowering effect on the usage of other structures regardless of team interaction. Over four months in our virtual team experiment, individuals with higher levels of CMC anxiety chose to not change their use of technology or 
participation behaviors, even with feedback (peer assessments) and the visible use of the technology in interactions by team members. As a result, nothing changed for these participants for the duration of the project.

Implications for Research. Prior research focused on the impact of CMC anxiety on the satisfaction or use of various media [14], [64]. The current study sheds light on earlier findings by examining not only use of CMC structures as influenced by CMC anxiety, but also on the specific nature of that use. It provides a deeper understanding of the changes in participation behavior in terms of the quality and quantity of participation, rather than solely on the amount of communication. Our research shows that there is a differential effect of CMC anxiety on the types (task or social) of communication behavior in which anxious individuals engage, as well as less contribution. So although prior research suggests that use of CMC can mitigate or exacerbate CMC anxiety, the current study specifically examines how this happens, in the context of a virtual project team. Thus, the current study provides evidence of the value of being more specific about the nature of CMC use in future research.

This research also studies the phenomenon of CMC anxiety over time, with multiple measures of outcome variables to examine the persistence of CMC anxiety effects. The current study shows that over time, the effects of CMC anxiety on participation behavior in a virtual team are relatively consistent. So although the nature of the subtasks within the project may change, the relative differences in participation between CMC anxious and less anxious individuals do not change. This suggests that these differences, strongly influenced by individual differences, may persist in spite of the structures available in the CMC—-parallelism, rehearsability, and 
reprocessability — that are designed to encourage and facilitate more open and beneficial communication behaviors. Furthermore, these CMC structures may actually provide the ability for the CMC anxious person to manipulate the nature of their interaction, to appear to be more involved in the team, while in reality they are imparting messages of limited benefit to the performance of the virtual team.

It is important to acknowledge the role that the CMC features could have played in these results. For example, it is likely that the rehearsability and parallelism provided by the technology allowed the more anxious individuals to participate in a manner of their choosing, minimizing obvious communication apprehensive behaviors such as pauses (or delays in a virtual environment), while providing interactions that appear to support team activity [54]. Furthermore, the inclusion of reprocessability features allowed the minimization of other communication apprehensive behaviors such as recall errors and lower message relevance by examining and copying prior messages. However, although CMC features provide the ability for anxious individuals to appear to be interacting the same as less anxious individuals, it may not necessarily be the case when the actual content of the messages is examined. The relatively lower level of task-oriented communication could be particularly problematic in virtual teams, as much of their early communication tends to be more task-oriented in nature [78] and taskoriented communication is clearly an important indicator of contribution and performance [57]. It is quite possible that different CMC features could lead to different relationships, highlighting the importance of considering the characteristics of the IT artifact as an important element of CMC research [81], [82]. 
Finally our results identify an important source of structure, characteristics of the individual, which can guide or constrain behavior, particularly the choice of other structures for usage and the manner of that usage. Although prior research has examined team, technology, task, and organizational structures that are enacted by teams as they work on tasks, this research identifies how individual structures can influence the manner in which these other structures may or may not be used. Furthermore, we see the strong enduring effect of these individual structures as they influence ongoing behavior in the virtual team. It is clear that the identification of individual characteristics as structures that influence behavior is important when attempting to understand the strengths and limitations of other sources of structures in the virtual team environment and how these other structures are perceived and used. Future research should incorporate individual structures as important aspects of the team communication/interaction process.

Implications for Practice. This research also has implications for practice regarding the reliance on CMC to overcome certain individual characteristics and the use of interventions to minimize the impact of CMC anxiety on virtual team outcomes. Although it may be that the use of CMC is beneficial for overcoming physical or cognitive limitations for virtual team performance, care should be taken to understand the potential unintended effects of the implementation of this type of technology. In this study, it was initially thought that the use of CMC would allow all individuals to participate equally and democratically on their team projects, however, the unintended result was that some of the individuals (CMC anxious), while seeming to interact like the others, were really not contributing to the team interaction as observed in the transcript coding. This suggests that organizations should consider that CMC technology may unintentionally serve to mask actual participation and contribution on a virtual team. This 
highlights the potential benefits of team leaders and role definitions for virtual teams, such that participation and contribution can be more easily seen, assessed, and ascribed to virtual team members [83], [84], [85].

This research also raises the possibility of exploring interventions associated with participation on a virtual team. Two key options exist. First, organizations can pre-screen virtual team participants in order to optimize participation. In this way, an organization can screen out CMC anxious individuals (if possible) in order to increase task-related and novel communication. At the very least, an organization can insure that most members of the team have low CMC anxiety, thereby increasing quantity and quality of participation and subsequently, overall virtual team performance. Although this option would likely have a positive impact on virtual team performance, it also carries ethical concerns and entails a tradeoff between suboptimal selection of (expert) team members and optimal participation. A second option is to design and administer training and intervention programs to help CMC anxious individuals compensate for their anxiety and to provide expected participation norms in CMC environments. In the long run, this appears to be a more viable solution, but will require additional research in order to understand which, if any, interventions are most appropriate.

Limitations. Although these findings extend what we know about CMC anxiety and CMC structures as they relate to participation in a virtual team, there are limitations to this research that must be considered. First, our subjects were students and of primary concern is the degree to which they were engaged with the project through the duration of the study. We attempted to maximize interest in the project by assessing a grade for performance at an individual level. 
Also, participants had graded deliverables required throughout the duration of the project, ensuring that there would be continued motivation to work on the project and do well. Further, the task was highly relevant for their career aspirations as information systems professionals [86]. An examination of the messages sent and words per message by phase suggests that individuals actually became more involved with the project over time as these outcome measures generally increased over the duration of the project. Therefore, we feel confident that participants were appropriately motivated to engage and interact during the research timeframe.

This limitation also suggests a corollary concern - the use of students as subjects. Given our focus on individual characteristics, virtual team communication behaviors, and performance assessments, it seems reasonable that students are a representative sample as they embody the characteristics, engaged in the behaviors, and their performance was assessed [87]. Considering the manner in which student participants interact and engage in classroom project teams, it is likely fair to say that communication and evaluation apprehensive adults working on real world teams would have felt more performance pressure than our subjects did, as their livelihood could have depended on the project outcomes. As a result, we believe it is reasonable to assume that the greater pressure to participate properly and perform well on organizational teams should have an even stronger effect than we observed.

A final limitation is that the subjects could have potentially interacted using other means that were not captured by the study's CMC. To minimize the risk of this limitation, participants were told frequently that the study CMC was the only allowable medium for project communication. Furthermore, transcripts revealed that participants were true to the spirit of the study. The 
transcripts show that several participants did request telephone numbers, email addresses, or instant messenger screen names to identify an alternative form of communication. However, in every case another team member reminded the team of the project "rules" that all interaction was to occur over the CMC provided in the study. It is also possible that some team members who were co-located may have interacted in person. In fact, one team did have a "synchronous meeting” where two members met in a library, and interacted over the CMC with members from the other universities on their team in real time. This team was dropped from the analysis, and there is no evidence that any other teams attempted this type of person-to-person interaction. As a result, we feel confident that the remainder of the teams completed their interactions primarily over the CMC technology provided to them.

Suggestions for Future Research. Our results suggest several avenues for future research. First, we examined the manner of participation and contribution of CMC anxious individuals to a virtual team project. However, although team members rated these CMC anxious individuals lower, it is unclear if this rating was due to the number of messages sent, the overabundance of social messages sent in compensation, the lack of novelty or low contribution value of the messages sent, or the actual perception of CMC anxiety. Additional research could examine the degree to which CMC anxious individuals are able to successfully minimize the appearance of anxiety to their team members, how team members perceive and recognize CMC anxious behaviors, and how these behaviors contribute to the development of team trust and cohesion or other determinants of team performance that are dependent on perceptions of team members. Second, although outcome measures suggest that CMC anxiety had an effect over the duration of the study, future research could examine this explicitly, to see if it is ongoing levels of CMC 
anxiety that caused the persistent communication behaviors, or if it is the case that, early on, individuals adopted a manner of participation, and re-enacted it over time. Thus, teasing out which of the structures is most relevant, and when, could be particularly valuable. Third, research on CMC and collaborative technologies should examine the role of feedback and monitoring systems in highlighting and reporting on the types of interactions observed in this study. It is possible that the provision of feedback in terms of participation quality and quantity might influence participation behaviors in a way more beneficial to a virtual team. Finally, additional research investigating the efficacy of interventions with respect to reducing CMC anxiety and improving the quality of participation would have theoretical and practical implications (for example, by team leaders, as explored by Thomas and Bostrom [88]). In the current study, we examined the relationship between CMC anxiety and time. Future work should investigate the impact of training, for example, on CMC anxiety-related behaviors. 


\section{References}

[1] R. A. Henry, "Improving group judgment accuracy: Information sharing and determining the best member," Organizational Behavior and Human Decision Processes, vol. 62, pp. $190-197,1995$.

[2] G. Stasser, "Information salience and the discovery of hidden profiles by decisionmaking groups: A thought experiment," Organizational Behavior and Human Decision Processes, vol. 52, pp. 156-181, 1992.

[3] A. M. Townsend, S. M. DeMarie, and A. R. Hendrickson, "Virtual teams: Technology and workplace of the future," Academy of Management Executive, vol. 12, pp. 17-29, 1998.

[4] J. R. Mesmer-Magnus, L. A. DeChurch, M. Jimenez-Rodriguez, J. Wildman, and M. Shuffler, "A meta-analytic investigation of virtuality and information sharing in teams," Organizational Behavior and Human Decision Processes, vol. 115, pp. 214—225, 2011.

[5] J. Lipnack and J. Stamps, Virtual teams: Reaching across space, time, and organizations with technology. New York, NY: John Wiley and Sons, 1997.

[6] A. Powell, G. Piccoli, and B. Ives, "Virtual teams: A review of current literature and directions for future research," Database, vol. 35, pp. 6-36, 2004.

[7] J. Radigan, "Remote possibilities," CFO Magazine, vol. 17, pp. 5—6, 2001.

[8] L. L. Gilson, M. T. Maynard, N. C. J. Young, M. Vartiainen, and M. Hakonen, "Virtual teams research: 10 years, 10 themes, and 10 opportunities," Journal of Management, vol. 41, pp. 1313-1337, 2015.

[9] K. Brownson, "The benefits of a work-at-home program," The Health Care Manager, vol. 23, pp. 141-144, 2004.

[10] J. Johnson, "The costs and benefits of remote workers," Network World, vol. 21, p. 24, 2004.

[11] A. R. Dennis and M. J. Garfield, "The adoption and use of gss in project teams: Toward more participative processes and outcomes," MIS Quarterly, vol. 27, pp. 289—323, 2003.

[12] S. S. K. Lam, "The effects of group decision support systems and task structures on group communication and decision quality," Journal of Management Information Systems, vol. 13, pp. 193-215, 1997.

[13] L. Sproull and S. Kiesler, Connections: New ways of working in the networked organization. Cambridge, MA: MIT Press, 1991.

[14] S. A. Brown, R. M. Fuller, and C. Vician, "Who's afraid of the virtual world? Anxiety and computer-mediated communication," Journal of the Association for Information Systems, vol. 5, pp. 79-107, 2004.

[15] E. Karahanna, M. Ahuja, M. Srite, and J. Galvin, "Individual differences and relative advantage: The case of gss," Decision Support Systems, vol. 32, pp. 327-341, 2002.

[16] V. L. Bartelt and A. R. Dennis, "Nature and nurture: The impact of automaticity and the structuration of communication on virtual team behavior and performance," MIS Quarterly, vol. 38, pp. 521-538, 2014.

[17] M. R. Hovde, "Factors that enable and challenge international engineering communication: A case study of a united states/british design team," IEEE Transactions on Professional Communication, vol. 57, pp. 242-265, 2014.

[18] F. Olivera, P. S. Goodman, and S. Swee-Lin Tan, "Contribution behaviors in distributed environments," MIS Quarterly, vol. 32, pp. 23—42, 2008. 
[19] P. E. Brewer, A. Mitchell, R. Sanders, P. Wallace, and D. D. Wood, "Teaching and learning in cross-disciplinary virtual teams," IEEE Transactions on Professional Communication, vol. 58, pp. 208-229, 2015.

[20] E. Koh and J. Lim, "Too early, too bad: Uncovering and understanding the initial participation paradox in technology-mediated learning teams," IEEE Transactions on Professional Communication, vol. 55, pp. 55-84, 2012.

[21] R. J. Ocker and J. Fjermestad, "Communication differences in virtual design teams: Findings from a multi-method analysis of high and low performing experimental teams," ACM SIGMIS Database, vol. 39, pp. 51-67, 2008.

[22] P. Weimann, M. Pollock, E. Scott, and I. Brown, "Enhancing team performance through tool use: How critical technology-related issues influence the performance of virtual project teams," IEEE Transactions on Professional Communication, vol. 56, pp. 332353, 2013.

[23] H. J. Han, S. R. Hiltz, J. Fjermestad, and Y. Wang, "Does medium matter? A comparison of initial meeting modes for virtual teams," IEEE Transactions on Professional Communication, vol. 54, pp. 376-391, 2011.

[24] G. DeSanctis and M. S. Poole, "Capturing the complexity in advanced technology use: Adaptive structuration theory," Organization Science, vol. 5, pp. 121—147, 1994.

[25] R. M. Fuller and A. R. Dennis, "Does fit matter? The impact of task-technology fit and appropriation on team performance in repeated tasks," Information Systems Research, vol. 20, pp. 2-17, 2009.

[26] A. R. Dennis, R. M. Fuller, and J. S. Valacich, "Media, tasks, and communication processes: A theory of media synchronicity," MIS Quarterly, vol. 32, pp. 575—600, 2008.

[27] L. Schweitzer and L. Duxbury, "Conceptualizing and measuring the virtuality of teams," Information Systems Journal, vol. 20, pp. 267—295, 2010.

[28] J. F. Nunamaker, A. R. Dennis, J. S. Valacich, D. R. Vogel, and J. F. George, "Electronic meeting systems to support group work," Communications of the ACM, vol. 34, pp. 4061, 1991.

[29] H. H. Clark and S. E. Brennan, "Grounding in communication," in Perspectives on socially shared cognition, L. B. Resnick, J. M. Levine, and S. D. Teasley, Eds., Washington, DC: American Psychological Association, 1991.

[30] C. Cornelius and M. Boos, "Enhancing mutual understanding in synchronous computermediated communication by training - trade-offs in judgmental tasks," Communication Research, vol. 30, pp. 147-177, 2003.

[31] B. E. Mennecke, "Using group support systems to discover hidden profiles: An examination of the influence of group size and meeting structures on information sharing and decision quality," International Journal of Human-Computer Studies, vol. 47, pp. 387-405, 1997.

[32] J. Mathieu, M. T. Maynard, T. Rapp, and L. Gilson, "Team effectiveness 1997—2007: A review of recent advancements and a glimpse into the future," Journal of Management, vol. 34, pp. 410—476, 2008.

[33] D. Te'eni, A. Sagie, D. G. Schwartz, N. Zaidman, and Y. Amichai-Hamburger, "The process of organizational communication: A model and field study," IEEE Transactions on Professional Communication, vol. 44, pp. 6—20, 2001. 
[34] E. Bradner, G. Mark, and T. D. Hertel, "Team size and technology fit: Participation, awareness, and rapport in distributed teams," IEEE Transactions on Professional Communication, vol. 48, pp. 68-77, 2005.

[35] M. H. Zack, "Interactivity and communication mode choice in ongoing management groups," Information Systems Research, vol. 4, pp. 207-239, 1993.

[36] A. J. Flanagin, H. S. Park, and D. R. Seibold, "Group performance and collaborative technology: A longitudinal and multilevel analysis of information quality, contribution equity, and members' satisfaction in computer-mediated groups," Communication Monographs, vol. 71, pp. 352-372, 2004.

[37] J. A. Goldberg, "A move toward describing conversational coherence," in Conversational coherence: Form, structure and strategy, R. T. Craig and K. Tracy, Eds., Beverly Hills: Sage Publications, 1983, pp. 25—45.

[38] A. P. Massey, M. M. Montoya-Weiss, and Y. T. Hung, "Because time matters: Temporal coordination in global virtual project teams," Journal of Management Information Systems, vol. 19, pp. 129-155, 2003.

[39] P. B. Lowry, N. C. Romano Jr, J. L. Jenkins, and R. W. Guthrie, "The CMC interactivity model: How interactivity enhances communication quality and process satisfaction in lean-media groups," Journal of Management Information Systems, vol. 26, pp. 155—195, 2009.

[40] V. J. Dubrovsky, S. Kiesler, and B. N. Sethna, "Internet communication," Journal of Communication, vol. 46, pp. 14-33, 1991.

[41] A. B. Hollingshead, "Information suppression and status persistence in group decision making: The effects of communication media," Human Communication Research, vol. 23, pp. 193-219, 1996.

[42] S. G. Straus, "Getting a clue: The effects of communication media and information distribution on participation and performance in computer-mediated and face-to-face groups," Small Group Research, vol. 27, pp. 115-142, 1996.

[43] G. P. Huber, J. S. Valacich, and L. M. Jessup, "A theory of the effects of group support systems on an organization's nature and decisions," in Group support systems: New perspectives, L. M. Jessup and J. S. Valacich, Eds., New York, NY: Macmillan Publishing Company, 1993, pp. 255—269.

[44] W. W. Huang and K. K. Wei, "An empirical investigation of the effects of group support systems (gss) and task type on group interactions from an influence perspective," Journal of Management Information Systems, vol. 17, pp. 181—206, 2000.

[45] W. W. Huang, "Impacts of gss generic structures and task types on group communication process and outcome: Some expected and unexpected research findings," Behaviour \& Information Technology, vol. 22, pp. 17-29, 2003.

[46] S. S. K. Lam and J. Schaubroeck, "Improving group decisions by better pooling information: A comparative advantage of group decision support systems," Journal of Applied Psychology, vol. 85, pp. 565-573, 2000.

[47] U. S. Murthy and D. S. Kerr, "Decision making performance of interacting groups: An experimental investigation of the effects of task type and communication mode," Information \& Management, vol. 40, pp. 351—360, 2003.

[48] F. Niederman and J. Bryson, "Influence of computer-based meeting support on process and outcomes for a divisional coordinating group," Group Decision and Negotiation, vol. 7, pp. 293-325, 1998. 
[49] R. J. Ocker, "Influences on creativity in asynchronous virtual teams: A qualitative analysis of experimental teams," IEEE Transactions on Professional Communication, vol. 48, pp. 22-39, 2005.

[50] B. J. Alge, C. Wiethoff, and H. J. Klein, "When does the medium matter? Knowledgebuilding experiences and opportunities in decision-making teams," Organizational Behavior and Human Decision Processes, vol. 91, pp. 26-37, 2003.

[51] J. Hedlund, D. R. Ilgen, and J. R. Hollenbeck, "Decision accuracy in computer-mediated versus face-to-face decision-making teams," Organizational Behavior and Human Decision Processes, vol. 76, pp. 30-47, 1998.

[52] J. R. Carlson and R. W. Zmud, "Channel expansion theory and the experiential nature of media richness perceptions," Academy of Management Journal, vol. 42, pp. 153—170, 1999.

[53] R. E. Carlson and D. G. Wright, "Computer anxiety and communication apprehension: Relationship and introductory college course effects," Journal of Educational Computing Research, vol. 9, pp. 329-338, 1993.

[54] J. A. Daly, "Communication apprehension in the college classroom," in New directions for teaching and learning: Communication issues in college teaching, J. M. Civikly, Ed., San Francisco: Jossey-Bass, 1986, pp. 21-31.

[55] T. J. Hurt, M. D. Scott, and J. C. McCroskey, Communication in the classroom. Reading, MA: Addison-Wesley, 1978.

[56] A. R. Dennis and B. H. Wixom, "Investigating the moderators of the group support systems use with meta-analysis," Journal of Management Information Systems, vol. 18, pp. 235-257, 2001.

[57] C. C. Cogliser, W. L. Gardner, M. B. Gavin, and J. C. Broberg, "Big five personality factors and leader emergence in virtual teams: Relationships with team trustworthiness, member performance contributions, and team performance," Group \& Organization Management, vol. 37, pp. 752-784, 2012.

[58] J. C. McCroskey, "Oral communication apprehension: A reconceptualization," Communication Yearbook, vol. 6, pp. 136-170, 1982.

[59] M. J. Brosnan, "Modeling technophobia: A case for word processing," Computers in Human Behavior, vol. 15, pp. 105-121, 1999.

[60] S. L. Chua, D. T. Chen, and A. F. L. Wong, "Computer anxiety and its correlates: A meta-analysis," Computers in Human Behavior, vol. 15, pp. 609-623, 1999.

[61] M. Igbaria, S. Parasuraman, and J. Baroudi, "A motivational model of microcomputer usage," Journal of Management Information Systems, vol. 13, pp. 127-143, 1996.

[62] C. R. Scott and S. C. Rockwell, "The effect of communication, writing, and technology apprehension on the likelihood to use new communication technologies," Communication Education, vol. 46, pp. 44-62, 1997.

[63] E. Karahanna, D. W. Straub, and N. L. Chervany, "Information technology adoption across time: A cross-sectional comparison of pre-adoption and post-adoption beliefs," MIS Quarterly, vol. 23, pp. 183-213, 1999.

[64] C. R. Scott and C. E. Timmerman, "Relating computer, communication, and computermediated communication apprehensions to new communication technology use in the workplace," Communication Research, vol. 32, pp. 683-725, 2005.

[65] M. M. Weil, L. D. Rosen, and S. E. Wugalter, "The etiology of computerphobia," Computers in Human Behavior, vol. 6, pp. 361-379, 1990. 
[66] R. F. Bales, "A set of categories for the analysis of small group interaction," American Sociological Review, vol. 15, pp. 257-263, 1950.

[67] Y. Yoo and M. Alavi, "Media and group cohesion: Relative influences on social presence, task participation, and group consensus," MIS Quarterly, vol. 25, pp. 371390, 2001.

[68] M. A. Marks, J. E. Mathieu, and S. J. Zaccaro, "A temporally based framework and taxonomy of team processes," Academy of Management Review, vol. 26, pp. 356-376, 2001.

[69] R. Y. Hirokawa, "Group communication and problem-solving effectiveness i: A critical review of inconsistent findings," Communication Quarterly, vol. 30, pp. 134-141, 1982.

[70] C. Pavitt and K. K. Johnson, "An examination of the coherence of group discussions," Communication Research, vol. 26, pp. 303-321, 1999.

[71] M. S. Poole, M. Holmes, R. Watson, and G. Desanctis, "Group decision support systems and group communication: A comparison of decision-making in computer-supported and nonsupported groups," Communication Research, vol. 20, pp. 176-213, 1993.

[72] J. Bourhis and M. Allen, "Meta-analysis of the relationship between communication apprehension and cognitive performance," Communication Education, vol. 41, pp. 6876, 1992.

[73] C. Vician and L. R. Davis, "Investigating computer anxiety and communication apprehension as performance antecedents in a computing-intensive learning environment," Journal of Computer Information Systems, vol. 43, pp. 51—57, 2002.

[74] T. Postmes, R. Spears, and M. Lea, "The formation of group norms in computer-mediated communication," Human Communication Research, vol. 26, pp. 341-371, 2000.

[75] R. M. Fuller, C. Vician, and S. A. Brown, "E-learning and individual characteristics: The role of computer anxiety and communication apprehension," Journal of Computer Information Systems, vol. 46, pp. 103-115, 2006.

[76] L. Chidambaram and L. L. Tung, "Is out of sight, out of mind? An empirical study of social loafing in technology-supported groups," Information Systems Research, vol. 16, pp. 149-168, 2005.

[77] B. H. Spitzberg and W. R. Cupach, Interpersonal communication competence. Beverly Hills, CA: Sage Publications, 1984.

[78] P. Kanawattanachai and Y. Yoo, "The impact of knowledge coordination on virtual team performance over time," MIS Quarterly, vol. 31, pp. 783—808, 2007.

[79] R. M. Walczuch and R. Watson, "Analyzing group data in mis research: Including the effect of the group," Group Decision and Negotiation, vol. 10, pp. 83-94, 2001.

[80] J. Nunnally, Psychometric theory, 2nd ed. New York, NY: McGraw-Hill, 1978.

[81] I. Benbasat and R. W. Zmud, "The identity crisis within the is discipline: Defining and communicating the discipline's core properties," MIS Quarterly, vol. 27, pp. 183—194, 2003.

[82] W. J. Orlikowski and C. S. Iacono, "Research commentary: Desperately seeking the "it" in it research - a call to theorizing the it artifact," Information Systems Research, vol. 12, pp. 121-134, 2001.

[83] U. Konradt and J. E. Hoch, "Work roles and leadership functions of managers in virtual teams," International Journal of E-Collaboration, vol. 3, pp. 16-35, 2007.

[84] C. Vician and G. DeSanctis, "The impact of role training in a user-driven group support system environment," Group Decision and Negotiation, vol. 9, pp. 275-296, 2000. 
[85] I. Zigurs and K. Kozar, "An exploratory study of roles in computer-supported groups," MIS Quarterly, vol. 18, pp. 277—299, 1994.

[86] G. DeSanctis, "Small group research in information systems: Theory and method," in The information systems research challenge: Experimental research methods, I. Benbasat, Ed., Boston, MA: Harvard Business School Press, 1989, pp. 53-82.

[87] D. Compeau, B. Marcolin, H. Kelley, and C. Higgins, "Generalizability of information systems research using student subjects—a reflection on our practices and recommendations for future research," Information Systems Research, vol. 23, pp. 1093-1109, 2012.

[88] D. M. Thomas and R. P. Bostrom, "Vital signs for virtual teams: An empirically developed trigger model for technology adaptation interventions," MIS Quarterly, vol. 34, pp. 115-142, 2010. 


\section{Appendix: Sample Coding Scheme}

\begin{tabular}{|c|c|c|c|c|c|c|c|c|c|c|c|c|c|c|c|c|}
\hline$\#$ & Subject & From & Body & \begin{tabular}{|l|} 
Codes: \\
$\mathbf{S}=$ Social \\
$\mathrm{T}=$ Task \\
$\mathbf{y}=$ \\
Incident \\
Number
\end{tabular} & - & 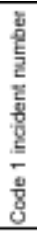 & $\frac{5}{5}$ & 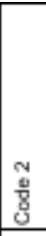 & 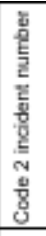 & 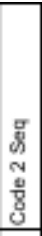 & 的 & 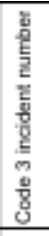 & $\begin{array}{l}\bar{g} \\
\delta \\
5 \\
\frac{6}{8} \\
\end{array}$ & \begin{tabular}{|l} 
\\
$\frac{6}{8}$ \\
\end{tabular} & 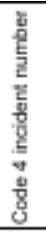 & 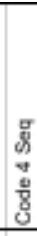 \\
\hline 1 & [team002] first one here & 107 & $\begin{array}{l}\text { yeah, so I figured our group could use a } \\
\text { message to liven it up a little bit, so here it is. }\end{array}$ & & $\mathrm{S}$ & 1 & 1 & & & & & & & & & \\
\hline 2 & [team002] Re: first one here & 110 & Here's some more livening it up! Cheers. & & $\mathrm{S}$ & 1 & 2 & & & & & & & & & \\
\hline 3 & [team002] Hey hey & 108 & $\begin{array}{l}\text { Just saying hey to my group.... I heard that } \\
\text { we have a deliverable due next friday.....any } \\
\text { idea what it is?? }\end{array}$ & & $\mathrm{S}$ & 1 & 3 & $\mathbf{T}$ & 1 & 1 & & & & & & \\
\hline 4 & [team002] Re: Hey hey & 110 & $\begin{array}{l}\text { I've posted the file that was on WebCT, I } \\
\text { guess it tells us all we need to know, though } \\
\text { we may find out more next week. Take care }\end{array}$ & & $\mathrm{T}$ & 1 & 2 & & & & & & & & & \\
\hline 5 & [team002] Time to meet & 108 & $\begin{array}{l}\text { Do you think that we might all be able to get } \\
\text { online at the same time in order to do this } \\
\text { first deliverable. How about Tuesday night } \\
\text { sometime...8 or } 9 \text { pm...? I think it might } \\
\text { benefit us to all be online and be able to } \\
\text { share ideas quickly. }\end{array}$ & & $\mathrm{T}$ & 2 & 1 & & & & & & & & & \\
\hline 6 & [team002] Re: Time to meet & 106 & $\begin{array}{l}\text { Tuesday night at 9pm is alright. Anything } \\
\text { late is fine. Can everybody else meet at this } \\
\text { time? Let's try to get started ASAP. }\end{array}$ & & $\mathrm{T}$ & 2 & 2 & & & & & & & & & \\
\hline 7 & [team002] Just a suggestion & 108 & $\begin{array}{l}\text { I think we need to come up with an E-R } \\
\text { model based on the handout that is posted. I } \\
\text { think we should all come on Tues and decide } \\
\text { how we are gonna set this up. We need to } \\
\text { pull out the entities and attributes from the } \\
\text { sheet. Tm thinking maybe we can split up the } \\
\text { work and then combine it somehow. Any } \\
\text { suggestions? }\end{array}$ & & $\mathrm{T}$ & 3 & 1 & $\mathrm{~T}$ & 2 & 3 & $\mathbf{T}$ & 4 & 1 & $\mathbf{T}$ & 5 & 1 \\
\hline 8 & [team002] Re: Just a suggestion & 109 & $\begin{array}{l}\text { Sounds like a plan, I can meet at } 9 \text {, so lets try } \\
\text { and shoot for that, we can discuss if there is a } \\
\text { possible way we can break it up or maybe } \\
\text { just make the rough outline with entities, } \\
\text { attributes, etc. See you all at } 9\end{array}$ & & $\mathrm{~T}$ & 2 & 4 & $\mathbf{T}$ & 5 & 2 & & & & & & \\
\hline
\end{tabular}

